\title{
Interfacultair vergelijken van prestatieverschillen op de voortgangstoets: onderzoek naar relevantie en haalbaarheid van het werken met referentiegroepen
}

\author{
A.N. Raat, J. Cohen-Schotanus
}

\section{Samenvatting}

Inleiding: De voortgangstoets (VGT) wordt afgenomen onder alle studenten geneeskunde in Maastricht, Nijmegen, Groningen en Leiden. Een ogenschijnlijk ideale situatie voor interfacultair vergelijkend onderzoek. Dergelijk onderzoek wordt echter bemoeilijkt doordat de betreffende jaargroepen van samenstelling verschillen. Homogeen samengestelde referentiegroepen zouden hieraan tegemoet kunnen komen. Aan de Faculteit der Medische Wetenschappen te Groningen is onderzocht in hoeverre het werken met deze groepen relevant en uitvoerbaar is.

Methode: Gebaseerd op het cursusjaar 2002/2003 is uit iedere jaargroep een referentiegroep geselecteerd. Vervolgens is de relevantie van het werken met deze groepen onderzocht door de gemiddelde eindscores van referentie- en niet-referentiestudenten met elkaar te vergelijken. De uitvoerbaarheid is beoordeeld aan de hand van een beschrijving van het selectieproces. Na een bijstelling van de selectiecriteria is de gehele procedure herhaald.

Resultaten: Voor wat betreft de relevantie blijkt de gemiddelde score van referentiestudenten bij 17 van de 24 vergelijkingen significant te verschillen van niet-referentiestudenten $(p<0.01)$. Voor wat betreft de uitvoerbaarheid blijkt een van de selectiecriteria zeer arbeidsintensief en gevoelig voor invloeden van het studieprogramma. De procedure is herhaald met loslating van dit criterium. De uitvoerbaarheid is hierdoor sterk toegenomen waarbij de gevonden verschillen tussen referentie- en niet-referentiestudenten bij 17 van de 24 vergelijkingen opnieuw significant zijn $(p<0.01)$.

Discussie: Het werken met referentiegroepen om prestatieverschillen op de VGT nauwkeuriger vast te stellen en interpretatieproblemen te voorkomen, lijkt gezien bovengenoemde bevindingen een zinvolle en haalbare onderneming. De aanbeveling tot vervolgonderzoek onder alle aan de VGT deelnemende faculteiten is overgenomen en in voorbereiding. (Raat AN, Cohen-Schotanus J. Interfacultair vergelijken van prestatieverschillen op de voortgangstoets: onderzoek naar relevantie en haalbaarheid van het werken met referentiegroepen. Tijdschrift voor Medisch Onderwijs 2005;24(5):212-219.)

\section{Inleiding}

De voortgangstoets (VGT) is een curriculumonafhankelijke kennistoets van de eindtermen geneeskunde. Sinds het studiejaar 1977/1978 is de voortgangstoets onlosmakelijk verbonden met het Maastrichtse toetsprogramma. ${ }^{1}$ In de loop der jaren zijn meerdere faculteiten in deze 'alomvattende cognitieve einddoeltoets'2 geïnteresseerd geraakt. Dit heeft geleid tot verschillende vormen van interfacultaire samenwerking. ${ }^{3}$ Zo worden de vragen niet langer alleen geconstrueerd in Maastricht, maar ook in Groningen en Nijmegen, en wordt de toets door Leiden aangekocht. Concreet betekent dit dat de voortgangstoets momenteel wordt voorgelegd aan ruim 5000 studenten geneeskunde in Maastricht, Nijmegen, Groningen en Leiden. Dit gebeurt vier maal per academisch jaar, in september, december, maart en mei, op exact hetzelfde moment, een woensdagmorgen van 9.00 tot 13.00 uur. Een ogenschijnlijk ideale situatie voor het 
doen van vergelijkend onderzoek. ${ }^{4-6}$ Reeds uitgevoerde vergelijkingen blijken echter bij herhaling te leiden tot discussie over de waarde die gehecht mag worden aan de gevonden verschillen. Dit wordt veroorzaakt doordat de te vergelijken jaargroepen in samenstelling uiteenlopen, ondermeer door verschillen in facultair beleid ten aanzien van recidivisten, zij-instromers en buitenlandse artsen. Deze ongelijkheid bemoeilijkt de interpretatie van gevonden prestatieverschillen. Zo kan een groep zij-instromers het jaargemiddelde van een bepaald cohort belangrijk beïnvloeden. In het huidig tijdsgewricht waarin veel waarde wordt gehecht aan prestatiecurves, en het naar buiten brengen daarvan, is het van belang dat interfacultair vergelijkend onderzoek vrij is van storende lokale invloeden. Om te komen tot een nauwkeuriger vergelijking van studieresultaten is daarom binnen de Werkgroep Interfacultaire Voortgangstoets (WIV) voorgesteld om te werken met referentiegroepen. Dit zijn homogeen samengestelde, onderling goed vergelijkbare groepen. Met het doen van dit voorstel is de vraag gerezen in hoeverre het werken met deze groepen relevant en uitvoerbaar is. Deze vraag is uitgewerkt aan de Faculteit der Medische Wetenschappen te Groningen. Achterliggende vragen hierbij zijn:

1. Is de gemiddelde score van de groep referentiestudenten significant anders dan die van de niet-referentiestudenten?

2. Is de omvang van de samengestelde referentiegroepen voldoende groot?

3. Is het praktisch uitvoerbaar om voor elk studiejaar een referentiegroep samen te stellen?

4. Behoeven de door de WIV voorgestelde selectiecriteria bijstelling en, zo ja, welke?

\section{Methode}

Het onderzoek is gebaseerd op gegevens over het studiejaar 2002/2003 waarbij voor iedere jaargroep, jaar één tot en met zes, een referentiegroep is samengesteld. Bij het samenstellen van de groepen is in eerste instantie uitgegaan van de door de WIV voorgestelde selectiecriteria. Bij het vaststellen van deze criteria heeft men beoogd alleen die studenten te includeren die het reguliere programma doorlopen binnen de daarvoor gestelde reguliere termijn van zes jaar, zonder dat daar speciale regelingen voor worden getroffen. Dit heeft geleid tot de volgende criteria:

- Nominale studieduur, gerekend vanaf studiejaar één.

- VGT-norm behaald van het voorgaande studiejaar.

- Voldoende studiepunten behaald (80\%) in het voorgaande studiejaar.

Met nominaal wordt hier bedoeld dat het aantal jaren dat men staat ingeschreven als student geneeskunde overeenkomt met het studiejaar dat men in het curriculum heeft bereikt. Op deze wijze worden de studenten met studievertraging of -versnelling, zoals de zij-instromers, uitgesloten. Om te voorkomen dat de referentiegroepen hierdoor te gering van omvang zullen zijn, heeft de WIV voorafgaand aan het onderzoek een minimale omvang voorgesteld van ten minste 100 studenten.

De selectie van referentiestudenten is uitgevoerd onder de deelnemers aan de VGT in september 2002. Als peildatum voor het behalen van studieresultaten in het voorgaande studiejaar is gekozen voor 1 september 2002. De groepen zijn bepaald met behulp van het studentregistratieprogramma ProgRESS. Dit programma biedt de mogelijkheid een overzicht te genereren waarbij jaar van instroom en individuele studentresultaten aan elkaar zijn gekoppeld. Aan de hand van deze overzichten zijn de referentiestudenten, deels handmatig, geselecteerd en zijn de verschillende groepen samengesteld. 
De relevantie van het werken met deze groepen is onderzocht door de gemiddelde eindscores van referentie- en niet-referentiestudenten met elkaar te vergelijken en te beoordelen in hoeverre deze significant van elkaar verschillen. De achterliggende gedachte hierbij is dat het werken met referentiegroepen relatief weinig toevoegde waarde heeft als er geen significante verschillen kunnen worden geconstateerd. De uitgevoerde vergelijking is getoetst met behulp van een t-toets. Toetsing van de verschillen tussen de referentiestudenten en het totaal aantal deelnemers is achterwege gelaten. De reden hiervoor is gelegen in het feit dat de groep referentiestudenten telkens een subgroep is van het totaal aantal deelnemers.

De uitvoerbaarheid van het werken met referentiegroepen is beoordeeld aan de hand van een beschrijving van het selectieproces. Na een bijstelling van de selectiecriteria is de gehele procedure herhaald.

\section{Resultaten}

Is de gemiddelde score van de groep referentiestudenten significant anders dan die van de niet-referentiestudenten? Om antwoord te krijgen op deze onderzoeksvraag zijn de betreffende scores met elkaar vergeleken. In tabel 1 zijn de resul-

Tabel 1. Vergelijking gemiddelde eindscores referentiestudenten $(r)$ met niet-referentiestudenten $(n-r)$. Selectie op basis van drie criteria, studiejaar 2002/2003.

\begin{tabular}{lcccccc}
\hline Jaar & VGT & $\mathbf{M}(\mathbf{r})$ & $\mathbf{M}(\mathbf{n}-\mathbf{r})$ & $\mathbf{t}$ & $\mathbf{d f}$ & $\mathbf{p}$ \\
\hline 1 & sept. 02 & 12.50 & 14.44 & -1.68 & 364 & .093 \\
& dec. 02 & 15.43 & 15.33 & 0.070 & 347 & .944 \\
& mrt. 03 & 20.43 & 16.22 & 2.237 & 321 & .026 \\
& mei 03 & 29.55 & 22.57 & 2.899 & 323 & .004 \\
& sept. 02 & 24.66 & 23.00 & 1.226 & 277 & .221 \\
& dec. 02 & 35.25 & 26.38 & 5.763 & 284 & .000 \\
& mrt. 03 & 39.34 & 29.29 & 5.931 & 289 & .000 \\
& mei 03 & 50.12 & 36.49 & 6.461 & 287 & .000 \\
& sept. 02 & 43.46 & 36.65 & 3.250 & 228 & .001 \\
& dec. 02 & 54.86 & 44.28 & 4.547 & 229 & .000 \\
& mrt. 03 & 60.36 & 44.23 & 6.405 & 219 & .000 \\
& mei 03 & 68.02 & 50.61 & 6.396 & 223 & .000 \\
& sept. 02 & 60.76 & 51.63 & 4.217 & 248 & .000 \\
& dec. 02 & 81.91 & 64.34 & 6.629 & 226 & .000 \\
& mrt. 03 & 74.75 & 64.13 & 3.618 & 181 & .000 \\
& mei 03 & 74.35 & 63.45 & 4.039 & 186 & .000 \\
5 & sept. 02 & 78.28 & 64.51 & 64.51 & 185 & .000 \\
& dec. 02 & 89.15 & 75.67 & 75.67 & 201 & .000 \\
& mrt. 03 & 92.07 & 77.81 & 77.81 & 222 & .002 \\
& mei 03 & 92.07 & 80.32 & 80.32 & 224 & .003 \\
& sept. 02 & 86.02 & 74.44 & 3.788 & 177 & .000 \\
& dec. 02 & 91.41 & 84.51 & 1.785 & 177 & .076 \\
& mrt. 03 & 88.20 & 85.12 & 0.758 & 166 & .449 \\
& mei 03 & 83.71 & 83.33 & 0.103 & 149 & .918 \\
\hline \multirow{4}{*}{6} & & & & &
\end{tabular}


taten van deze vergelijking weergegeven. De gemiddelde eindscore van de referentiestudenten blijkt bij 17 van de 24 vergelijkingen positief significant te verschillen van de niet-referentiestudenten $(\mathrm{p}<0.01)$. In studiejaar twee tot en met vijf geven de referentiegroepen, met uitzondering van de tweedejaars VGT in september, een consistent en significant ander beeld. Dit lijkt veelbelovend te zijn voor de relevantie van het werken met referentiegroepen. De uitkomsten betreffende studiejaar één, vijf en zes dienen echter terughoudend te worden geïnterpreteerd. Dit heeft te maken met de aard en omvang van de samengestelde referentiegroepen, hetgeen leidt naar de overige onderzoeksvragen betreffende de haalbaarheid van het werken met referentiegroepen.

Is de omvang van de samengestelde referentiegroepen voldoende groot, $n>100$ ?

De voorgestelde selectiecriteria leiden in studiejaar één tot en met vier tot referentiegroepen van voldoende omvang. De referentiegroep met betrekking tot jaar één is echter zeer groot, 311. In jaar vijf en zes daarentegen zijn de referentiegroepen erg klein, resp. 29 en 48. In tabel 2 is per studiejaar de omvang weergegeven van de verschillende referentiegroepen, zowel absoluut als relatief.

Het grote aantal referentiestudenten in studiejaar één wordt verklaard doordat twee van de drie criteria betrekking hebben op het voorgaande studiejaar. Voor het eerste studiejaar zijn deze criteria niet relevant. Bij gevolg kunnen bijna alle eerstejaars worden geïncludeerd. Slechts een kleine groep studenten, voornamelijk recidivisten, voldoet niet aan het criterium betreffende de nominale studieduur. Zoals op basis van de gekozen selectiecriteria valt te verwachten, wordt het aantal referentiestudenten jaarlijks kleiner. Opmerkelijk is echter de plotselinge daling van het aantal referentiestudenten aan het begin van jaar vijf. Het geringe aantal referentiestudenten in jaar vijf en zes kan worden verklaard doordat het vierde studiejaar in het Groninger curriculum een aanmerkelijk andere opzet kent dan de voorgaande studiejaren. De studenten lopen in deze periode veelal stage, al dan niet in het buitenland, zijn bezig met het doen van wetenschappelijk onderzoek, het volgen van keuzecursussen, et cetera. Nasporingen onder het grote aantal geëxcludeerde niet-referentiestudenten wijzen uit dat veel van deze studenten hierdoor niet kunnen voldoen aan het criterium voldoende studiepunten behaald ( $80 \%)$ in het voorgaande studiejaar. Althans niet op de peildatum van 1 september 2002. Een student die op 15 september zijn wetenschappelijk onderzoek administratief afrondt en 14 studiepunten laat registreren, valt buiten de referentiegroep. Het criterium 'voldoende studiepunten behaald in het voorgaande studiejaar' blijkt hiermee niet alleen van invloed op de omvang van de referentiegroepen, maar tevens gevoelig voor invloed van het jaarprogramma. Bij het doen van interfacultair vergelijkend onderzoek is deze invloed een onwenselijk gegeven daar dit kan leiden tot nieuwe interpretatieproblemen.

Tabel 2. Omvang referentiegroepen per studiejaar. Aantal deelnemende referentiestudenten ( $r$ ), zowel absoluut als relatief, en totaal aantal deelnemers (tot), studiejaar 2002/2003, VGT september.

\begin{tabular}{|c|c|c|c|c|c|c|c|c|c|c|c|c|}
\hline Jaar & 1 & & 2 & & 3 & & 4 & & 5 & & 6 & \\
\hline$r$ & 311 & $85 \%$ & 210 & $75 \%$ & 149 & $65 \%$ & 117 & $47 \%$ & 29 & $16 \%$ & 48 & $27 \%$ \\
\hline tot & 366 & & 279 & & 230 & & 250 & & 187 & & 179 & \\
\hline
\end{tabular}




\section{Is het praktisch uitvoerbaar om voor elk studiejaar een referentiegroep samen te stellen?}

$\mathrm{Na}$ het nemen van wat technische hindernissen en het doen van tijdrovend handwerk is het mogelijk gebleken om referentiegroepen samen te stellen voor alle zes de studiejaren, gebaseerd op door de WIV voorgestelde criteria. Het criterium 'voldoende studiepunten behaald $(80 \%)$ in het voorgaande studiejaar' blijkt ook voor wat betreft de praktische uitvoerbaarheid een complicerende rol te spelen. Zo is het niet eenvoudig gebleken de voor dit criterium benodigde bestandsgegevens te koppelen. Daarbij blijkt het criterium sterk afhankelijk van een tijdige administratie van de studieresultaten. Op de valreep behaalde studiepunten, eind augustus, worden soms begin september ingeboekt. Dit leidt te gemakkelijk tot een foutieve indeling. Herstel van dergelijke onjuiste indelingen kost veel tijdrovend handwerk.

\section{Behoeven de door de WIV voorgestelde selectiecriteria bijstelling, en zo ja welke?} Bovengenoemde bevindingen leiden tot een bevestigend antwoord. Het criterium 'voldoende studiepunten behaald (80\%) in het voorgaande studiejaar' blijkt van negatieve invloed te zijn op de relevantie en uitvoerbaarheid van het werken met referentiegroepen. De gehele onderzoeksprocedure is daarom herhaald met loslating van dit selectiecriterium. In de nieuwe onderzoekssituatie zijn de referentiegroepen bepaald volgens de twee overige, door de WIV vastgestelde criteria:
- Nominale studieduur, gerekend vanaf studiejaar één.

- VGT-norm behaald van het voorgaande studiejaar.

\section{Herhaling van de onderzoeksprocedure met bijgestelde criteria.}

Bij de herhaling van de procedure is in het kader van de haalbaarheid opnieuw gekeken naar de omvang van de verschillende referentiegroepen. Deze blijkt voor alle zes de groepen van voldoende grootte ( $\mathrm{n}>100)$ om statistisch te kunnen worden bewerkt. In tabel 3 wordt per studiejaar een overzicht gegeven van de omvang van de verschillende referentiegroepen, zowel absoluut als relatief.

De kleinste referentiegroepen, jaar vijf en zes, bestaan uit respectievelijk $60 \%$ en $61 \%$ van het totaal aantal deelnemers aan de VGT. Deze toename in omvang is een direct gevolg van het loslaten van het criterium 'voldoende studiepunten behaald in het voorgaande studiejaar', waarmee ook de storende invloed van het jaarprogramma is opgeheven. Voor het werken met interfacultair goed vergelijkbare referentiegroepen is het kunnen vermijden van locale, facultaire invloeden van cruciaal belang.

Ook de praktische uitvoerbaarheid is met het loslaten van bovengenoemd criterium sterk toegenomen. Technisch gezien blijken de benodigde bestanden beduidend sneller en gemakkelijker te kunnen worden gekoppeld. De afhankelijkheid van de studentadministratie blijkt eveneens aanzienlijk minder groot. Dit is een belangrijk bedrijfseconomisch gegeven daar de

Tabel 3. Omvang referentiegroepen op basis van herziene criteria. Aantal referentiestudenten ( $r$ ), absoluut en relatief, en totaal aantal deelnemers (tot), studiejaar 2002/2003, VGT september.

\begin{tabular}{|c|c|c|c|c|c|c|c|c|c|c|c|c|}
\hline Jaar & 1 & & 2 & & 3 & & 4 & & 5 & & 6 & \\
\hline$r$ & 311 & $85 \%$ & 223 & $80 \%$ & 177 & $77 \%$ & 160 & $64 \%$ & 112 & $60 \%$ & 110 & $61 \%$ \\
\hline tot & 366 & & 279 & & 230 & & 250 & & 187 & & 179 & \\
\hline
\end{tabular}


referentiegroepen bij een interfacultaire onderzoeksopzet relatief snel en eenvoudig moeten kunnen worden samengesteld.

In het kader van de relevantie zijn bij de herhaling van de procedure de gemiddelde eindscores van de referentiestudenten opnieuw vergeleken met die van de niet- referentiestudenten. In tabel 4 zijn de resultaten van deze vergelijking weergegeven. Met het herzien van de criteria blijkt de gemiddelde eindscore van de referentiestudenten wederom bij 17 van de 24 vergelijkingen positief significant te verschillen van de nietreferentiestudenten $(\mathrm{p}<0.01)$. De identieke gegevens in de tabellen 1 en 4 betreffende studiejaar één, maken duidelijk zichtbaar dat het voor het eerste studiejaar geen enkel verschil maakt of het criterium 'voldoende studiepunten behaald in het voorgaande studiejaar' wel of niet wordt meegenomen. Daarentegen zijn de verschillen met betrekking tot het zesde en laatste studiejaar in significantie toegenomen. De bevindingen met betrekking tot jaar vijf en zes kunnen minder terughoudend worden geïnterpreteerd. Deze groepen zijn na het herzien van de criteria van voldoende omvang om een verantwoorde interpretatie van de gegevens mogelijk te maken. Voor wat betreft de relevantie van het werken met referentiegroepen zijn de overwegend significante verschillen een veelbelovend gegeven.

Tabel 4. Vergelijking gemiddelde eindscores referentiestudenten $(r)$ met niet-referentiestudenten $(n-r)$. Selectie op basis van twee criteria, studiejaar 2002/2003.

\begin{tabular}{|c|c|c|c|c|c|c|}
\hline Jaar & VGT & $M(r)$ & $M(n-r)$ & $\mathbf{t}$ & df & $p$ \\
\hline \multirow[t]{4}{*}{1} & sept. 02 & 12.50 & 14.44 & -1.68 & 364 & .093 \\
\hline & dec. 02 & 15.43 & 15.33 & 0.070 & 347 & .944 \\
\hline & mrt. 03 & 20.43 & 16.22 & 2.237 & 321 & .026 \\
\hline & mei 03 & 29.55 & 22.57 & 2.899 & 323 & .004 \\
\hline \multirow[t]{4}{*}{2} & sept. 02 & 24.54 & 23.11 & 0.979 & 277 & .329 \\
\hline & dec. 02 & 34.74 & 26.42 & 5.095 & 284 & .000 \\
\hline & mrt. 03 & 38.65 & 29.89 & 4.875 & 289 & .000 \\
\hline & mei 03 & 49.25 & 37.36 & 5.324 & 287 & .000 \\
\hline \multirow[t]{4}{*}{3} & sept. 02 & 41.97 & 38.02 & 1.637 & 228 & .103 \\
\hline & dec. 02 & 53.10 & 44.58 & 3.235 & 229 & .001 \\
\hline & mrt. 03 & 57.90 & 43.46 & 4.935 & 219 & .000 \\
\hline & mei 03 & 65.73 & 50.09 & 5.015 & 223 & .000 \\
\hline \multirow[t]{4}{*}{4} & sept. 02 & 58.09 & 52.01 & 2.647 & 248 & .009 \\
\hline & dec. 02 & 78.65 & 61.40 & 5.749 & 226 & .000 \\
\hline & mrt. 03 & 73.78 & 60.38 & 4.308 & 181 & .000 \\
\hline & mei 03 & 71.58 & 62.17 & 3.271 & 186 & .001 \\
\hline \multirow[t]{4}{*}{5} & sept. 02 & 70.46 & 60.93 & 3.478 & 185 & .001 \\
\hline & dec. 02 & 83.10 & 71.43 & 4.688 & 201 & .000 \\
\hline & mrt. 03 & 88.22 & 71.87 & 5.927 & 222 & .000 \\
\hline & mei 03 & 87.61 & 76.62 & 4.291 & 224 & .000 \\
\hline \multirow[t]{4}{*}{6} & sept. 02 & 81.56 & 71.13 & 3.744 & 177 & .000 \\
\hline & dec. 02 & 88.66 & 82.91 & 1.756 & 177 & .081 \\
\hline & mrt. 03 & 89.95 & 79.67 & 2.978 & 166 & .003 \\
\hline & mei 03 & 85.38 & 80.68 & 1.474 & 149 & .143 \\
\hline
\end{tabular}




\section{Discussie}

Het interfacultair vergelijken van prestaties op de VGT vereist, gezien het hedendaagse belang dat publiekelijk wordt gehecht aan prestatiecurves, een zorgvuldige aanpak. Voor dergelijk onderzoek is het noodzakelijk te werken met onderling goed vergelijkbare jaargroepen, daar de huidige verschillen in de samenstelling van deze groepen de interpretatie van de uitkomsten bemoeilijken. Om te voorkomen dat facultair beleid ten aanzien van recidivisten, zij-instromers en buitenlandse artsen het jaargemiddelde van een bepaald cohort belangrijk beïnvloedt, is het van belang dat interfacultair vergelijkend onderzoek vrij is van storende lokale invloeden.

Homogeen samengestelde referentiegroepen zouden in deze behoefte kunnen voorzien. In dit onderzoek is nagegaan in hoeverre het werken met deze groepen relevant en uitvoerbaar is. Samengevat kan worden gesteld dat het werken met referentiegroepen een relevante en goed uitvoerbare onderneming lijkt te zijn, als de beoogde groepen zijn samengesteld op basis van de criteria:

- Nominale studieduur, gerekend vanaf studiejaar één.

- VGT-eindtermen behaald van het voorgaande studiejaar.

Met behulp van deze criteria worden alleen die studenten geselecteerd die het reguliere programma doorlopen binnen de daarvoor gestelde reguliere termijn van zes jaar, zonder dat daar speciale regelingen voor zijn getroffen. Deze homogeen samengestelde referentiegroepen kunnen worden vergeleken met op gelijke wijze samengestelde referentiegroepen van overige aan de VGT deelnemende faculteiten. Het interfacultair vergelijkend onderzoek naar prestatieverschillen op de VGT kan op deze wijze gevrijwaard worden van storende locale invloeden, waardoor men nauwkeuriger uitspraken kan doen over de vergeleken reguliere onderwijsprogramma's.

Deze veelbelovende uitkomst ten aanzien van het werken met referentiegroepen kent echter zijn beperkingen. Om daadwerkelijk een uitspraak te kunnen doen over een interfacultair bedoelde werkwijze, is het noodzakelijk om meerdere faculteiten bij de vergelijking te betrekken. Pas als de uitkomst van een interfacultaire vergelijking gebaseerd op referentiegroepen wordt afgezet tegen een standaardvergelijking, kan de beoogde meerwaarde van het werken met referentiegroepen worden geëvalueerd. Dit is echter een relatief grote onderneming die vraagt om een zorgvuldige voorbereiding. De kracht van deze (voor)studie is daarom gelegen in het feit dat de relevantie van een dergelijke onderneming is onderbouwd en op interfacultair niveau niet tijdrovend en kostbaar hoeft te worden gezocht naar de juiste selectiecriteria.

In vervolg op het hier beschreven onderzoek is een interfacultaire vergelijking in voorbereiding.

\section{Literatuur}

1. Vleuten CPM van der, Verwijnen GM, Wijnen WHFW. Fifteen years of experience with progress testing in a problem based curriculum. Med Teach 1996;18:1003-9.

2. Verhoeven B. Progress Testing: the utility of an Assessment concept [dissertation]. Groningen; Stichting Drukkerij Regenboog; 2003., 178.

3. Bulte JA, Ket P. Forum: Invoeren van de Maastrichtse voortgangstoets in andere faculteiten: J/O/? Tijdschrift voor Medisch Onderwijs 2000;19(1):31-7.

4. Bender W, Cohen-Schotanus J, Imbos Tj, Versfelt W, Verwijnen GM. Medische kennis bij studenten uit verschillende faculteiten: van hetzelfde laken een pak? Ned Tijdschr Geneeskd 1984: 128: 917-21.

5. Vleuten CPM van der, Verwijnen GM, Holdrinet RSG, Oeseburg B, Bulte JA, Leunissen RRM. Naar een interfacultaire voortgangstoets: resultaten van proefafnames. Bulletin Medisch Onderwijs 1995;15(1):1-7.

6. Albano MG, Cavallo F, Hoogenboom R, Magni F, Majoor G, Manenti F, et al. An international comparison of knowledge levels of medical students: The Maastricht progress test. Med Educ 1996;30:239-45. 


\section{De auteurs:}

Mw. drs. A.N. Raat, medewerker onderwijsontwikkeling bij de afdeling Onderwijsontwikkeling en Kwaliteitszorg, Onderwijsinstituut, Faculteit der Medische Wetenschappen, Rijksuniversiteit Groningen.

Mw. dr. J. Cohen-Schotanus, hoofd afdeling Onderwijsontwikkeling en Kwaliteitszorg, Onderwijsinstituut, $\mathrm{Fa}$ culteit der Medische Wetenschappen, Rijksuniversiteit Groningen.
Correspondentieadres:

Mw. drs. A.N. Raat, Rijksuniversiteit Groningen, FMW/ Onderwijsinstituut, A. Deusinglaan 1, 9713 AV Groningen, tel.:050-3638719,fax:050-3633865,a.n.raat@med. rug.nl.

\section{Summary}

Introduction: Four Dutch medical schools administer four jointly developed progress tests to all of their students annually. At first sight, this would seem to offer the perfect opportunity for comparative research. However, a complication is the different composition of cohorts in the four schools. This might be resolved by using homogeneous reference groups. The relevance and feasibility of this approach was tested at the Faculty of Medical Sciences of Groningen University.

Method: Reference groups were composed for each of the six years, based on data collected in 2002/2003. The relevance of using reference groups was examined by comparing the mean final scores of the reference and non-reference groups. The selection process was described to assess the feasibility of the process. After modification of the selection criteria the procedure was repeated.

Results: 17 out of 24 comparisons revealed significant differences $(p<0.01)$ between the mean scores of the reference groups and the non-reference groups. One of the selection criteria proved to be highly labour intensive and susceptible to curriculum effects. After removing this criterion, feasibility improved substantially, with again 17 out of 24 comparisons showing significant differences $(p<0.01)$ between reference and non-reference groups.

Conclusion: The results suggest that it is relevant and feasible to use reference groups to achieve greater accuracy in determining differences between medical schools in progress test results and prevent problems of interpretation. Preparations are underway for similar studies in all participating medical schools as was recommended on the basis of the results of this study. (Raat AN, Cohen-Schotanus J. A comparison of progress test results in different medical schools: the relevance and feasibility of using reference groups. Dutch Journal of Medical Education 2005;24(5):212-219.) 